\title{
Dermatitis Artefacta Mimicking Borderline Personality Disorder: Sometimes, Skin Could Be Misleading
}

\author{
Seshadri Sekhar Chatterjee ${ }^{1}$, Sayantanava Mitra ${ }^{2}$ \\ 'Department of Psychiatry, Medical College, Kolkata, ${ }^{2}$ Consultant Psychiatrist, Kolkata, India
}

Dermatitis artefacta lies in a gray zone, between the specialities of psychiatry and dermatology. The condition could mimic a number of other lesions and therefore is a source of much confusion in clinical practice. Here, we describe a case of dermatitis artefacta in an 11-years old girl, which resembled self-harming behavior in Borderline personality disorder. We then discuss how the two could be differentiated and why this becomes imperative while dealing with such cases.

KEY WORDS: Dermatitis artefacta; Self-injurious behavior; Borderline personality disorder.

\section{INTRODUCTION}

Lying at the interface between dermatology and psychiatry; dermatitis artefacta (DA) is an enigmatic entity, one excellent imitator and, therefore a source of great confusion for unsuspecting physicians as well as for trained specialists. The confusion and consequent misdiagnosis might unnecessarily increase morbidity and mortality of these patients. We describe here a classic case of DA, which closely mimicked deliberate self-harm (DSH) in patients with borderline personality disorder (BPD). Since BPD, with $60-80 \%$ DSH rates, ${ }^{1)}$ warrants separate and focussed attention; unscrambling it from DA becomes imperative.

\section{CASE}

An 11 year old Third-born rural Bengali girl from lower economic strata, with nil-contributory past/family/developmental history; visited psychiatry outdoors for sudden-onset multiple fine cuts on left forearm and forehead. She had reportedly been wearing full-sleeved clothes for last 1-2 weeks in hot summer and had changed her hairdo

\footnotetext{
Received: September 17, 2015 / Revised: December 1, 2015

Accepted: December 2, 2015

Address for correspondence: Sayantanava Mitra, MBBS, MD Psych, DNB Psych

Department of Psychiatry, Sarojini Naidu Medical College, 22/D/1

Aswini Dutta Road, Kolkata 700028, India

Tel: +91-8298187766

E-mail: sayantanava@gmail.com
}

to cover forehead, both going unnoticed until the mother found blood-stains on her sleeves; and fearing she had tried to kill herself, consulted us. However, history did not reveal behavioral disturbances, disruptions in activities of daily living, significant affective or psychotic symptoms. School-attendance, peer-interactions and biological functions were preserved. Her personality was unimpaired. On examination, forearm lesions were linear, horizontal and tailing towards right (dominant-hand). They were present in closely drawn pairs; a few having associated hesitation-cuts. Forehead lesions were vertical and tailed downwards. They were all superficial, in different stages of healing (Fig. 1). There were nil other physical abnormalities. Patient denied making any of the cuts, and claimed that they had appeared by themselves over last 7 days. When told that there was no such skin condition which would manifest like these, she became rigid in her opinion.

During the interview, she was oriented to time, place and person. She appeared relaxed; speech was soft/coherent/relevant, and no perceptual/thought abnormalities could be elicited. Her unusual indifference to these lesions was in stark contrast to her wounds. Even with deep probing, major stressors could not be identified. She was subsequently worked up for personality traits and intelligence. Her full scale intelligence quotient on Malin's intelligence scale for Indian children (MISIC) ${ }^{2)}$ was 88 , which indicated normal intelligence. Assessment on Junior Temperament and Character Inventory ${ }^{3)}$ failed to reveal significant impairment in any of the scales measur-

(a) This is an Open-Access article distributed under the terms of the Creative Commons Attribution Non-Commercial License (http://creativecommons.org/licenses/by-nc/4.0) which permits unrestricted non-commercial use, distribution, and reproduction in any medium, provided the original work is properly cited. 
ing novelty seeking, harm avoidance, reward dependence or persistence. Scores on Hamilton Anxiety Rating Scale (HAM-A $)^{4)}$ was 14 indicating mild anxiety; and on HamiIton Rating Scale for Depression ${ }^{5)}$ was 6 indicating no depression. We were unable to find any material gains from the lesions, after thorough clinical and historical evaluations.

The patient was admitted to an open ward along with her mother for the purpose of administering psychotherapy, and supervised initiation of pharmacotherapy. Dermatology consultation maintained a provisional diagnosis of DA after due considerations, and advised conservative management of the skin lesions. She was started on fluoxetine $10 \mathrm{mg}$, along with supportive psychotherapy and family therapy based on the advises of the treating team. Patient's denial of the origin of the lesions and their unpredictable occurrences proved a major hindrance to $\mathrm{ABC}$ analysis and behavior-based interventions; and initial focus was thus maintained on establishing rapport. She was discharged without development of fresh lesions after 7 days' of in-patient stay, and there had been nil fresh crops at 1 month's follow up. At follow up, her HAM-A score had reduced to 10 , and side-effects to pharmacotherapy were none. Her socio-occupational life remained was well-maintained.

\section{DISCUSSION}

DA applies only to conditions in which skin lesions appear in a mysterious ways while the patient denies all responsibilities for them. These often reflect deeply buried psychological distresses, which need to be sincerely sought after. ${ }^{6}$ Linear excoriations, inflicted through fingernails or sharp objects, are the second most common manifestation of DA after ulcers. ${ }^{7)}$ Interestingly, a large number of these patients visit dermatologists, for whom this condition remain a source of great discomfort and a diagnosis of exclusion. ${ }^{7)}$ The condition is diagnosed in dermatological practice using Gupta and Gupta's ${ }^{8)}$ classificatory system under "disorders associated with self-inflicted dermatoses", which is self-explanatory in a sense. Mean age of presentation has been put at around 20 years, with a female preponderance and a greater prevalence in lower socio-economic strata. ${ }^{7)}$ The history in these patients is usually "hollow"; 9 ) and those with an apparent cause as psychosis or malingering need to be excluded. ${ }^{7)}$ Diagnosing DA requires a high degree of suspicion, a meticulous appraisal of the dermatological signs and a detailed evaluation of psychological faculties. Similarly, management requires an eclectic combination of an empathetic patient-doctor relationship, a supportive environment, psychotherapeutic and pharmacological interventions, ${ }^{7)}$ thus entailing a proper liaison.

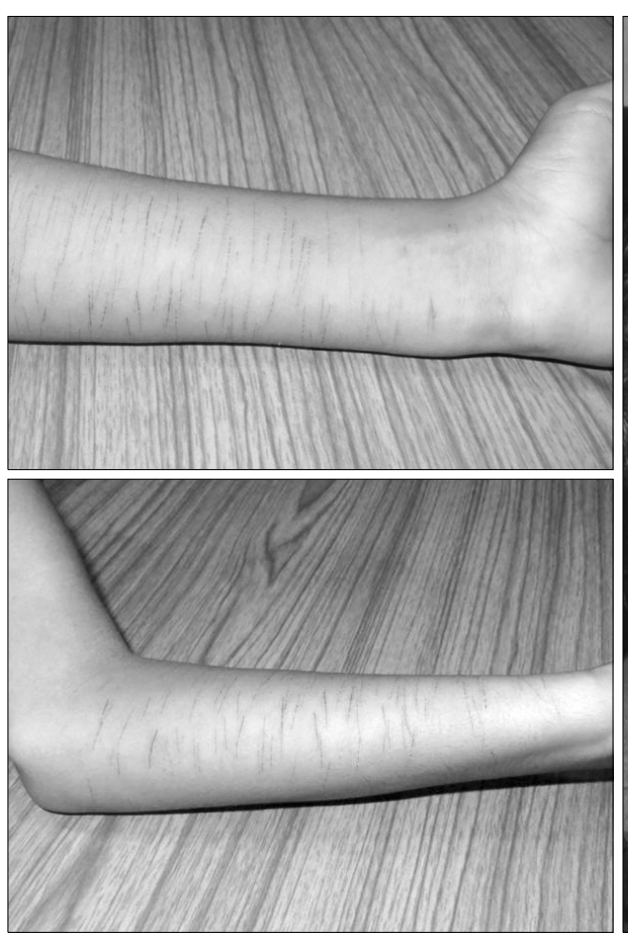

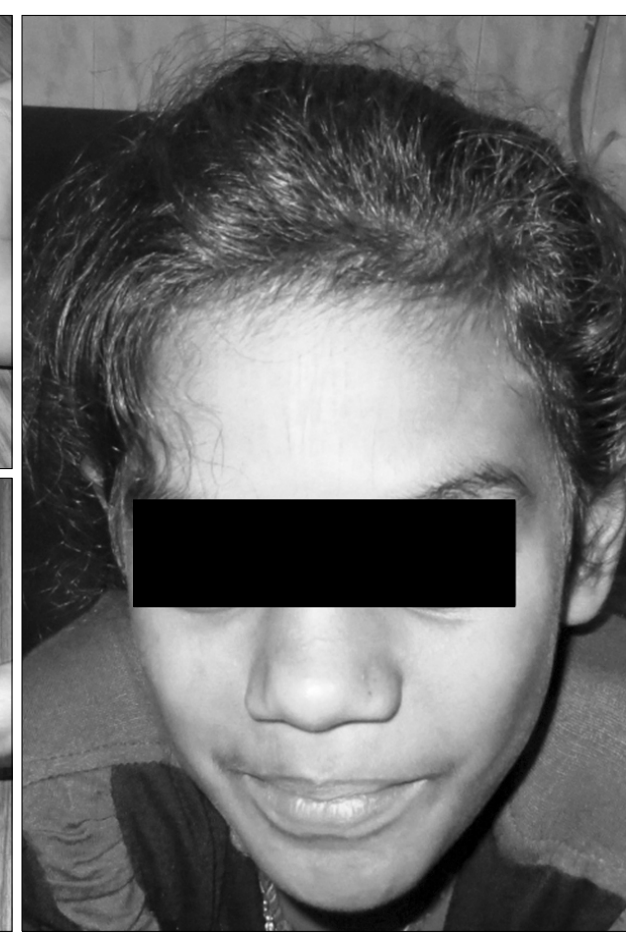

Fig. 1. Lesions of dermatitis artefacta in our patient, as described in the text. 
From a psychiatrist's perspective; lesions in our patient closely resembled hesitation cuts and DSH, generally seen in those with BPD. BPD is characterised by classical presentations of "a pervasive pattern of instability of interpersonal relationships, self-image, and affects, and marked impulsivity"10) with a central feature of emotional dysregulation. ${ }^{1)}$ DSH noted in BPD patients form an important dimension of this disorder and constitutes the chief reason for treatment utilization in this patient population. ${ }^{1)}$ Though termed "parasuicidal", thus signifying a lack of intent, such behaviors could nevertheless be fatal or at least a source of significant morbidity for the patient as well as his/her family. Such behaviors have been attributed to the inherent tendency towards experiential avoidance, escape learning and impulsivity in these patients, ${ }^{1)}$ and they require an assertive and active therapist. The demonstrated success of dialectical behavior therapy in managing BPD cases requires that they be identified at the earliest, before much damage has been incurred. ${ }^{11)} \mathrm{DSH}$ in DA, on other hand, is driven more by the underlying negative affect states, and cognitive-behavioral approach suits these patients more, within a passive yet empathetic psychiatrist-patient relationship. Differences also exist in the way these patients are managed pharmacologically. While stress and anxiety in DA would respond to SSRIs most of the time; they require extreme caution in BPD to avoid mood dysregulation and induced switch. ${ }^{12)}$

In our patient we had carefully ruled out malingering and other major psychiatric conditions through detailed clinical and psychometric evaluations to arrive at a diagnosis of DA. This was important, both for prognostication as well as for proper management. Our case reiterates the utility of detailed evaluation of DSH in practise, a need for liaison with dermatology, for the psychiatrist to be open to possibilities and be ready to go beyond what is seen. If diagnosed in time, DA can have a good outcome.

\section{REFERENCES}

1. Chapman AL, Specht MW, Cellucci T. Borderline personality disorder and deliberate self-harm: does experiential avoidance play a role? Suicide Life Threat Behav 2005;35: 388-399.

2. Malin AJ. Malin's intelligence scale for Indian children. Nagpur, India:Child Guidance Center;1969.

3. Luby JL, Svrakic DM, McCallum K, Przybeck TR, Cloninger CR. The Junior Temperament and Character Inventory: preliminary validation of a child self-report measure. Psychol Rep 1999;84:1127-1138.

4. Hamilton M. The assessment of anxiety states by rating. $\mathrm{Br}$ J Med Psychol 1959;32:50-55.

5. Hamilton M. A rating scale for depression. J Neurol Neurosurg Psychiatry 1960;23:56-62.

6. Ghosh S, Behere RV, Sharma P, Sreejayan K. Psychiatric evaluation in dermatology: an overview. Indian J Dermatol 2013;58:39-43.

7. Rodríguez Pichardo A, García Bravo B. Dermatitis artefacta: a review. Actas Dermosifiliogr 2013;104:854-866.

8. Gupta MA, Gupta AK. Psychodermatology: an update. J Am Acad Dermatol 1996;34:1030-1046.

9. Gandy DT. The concept and clinical aspects of factitial dermatitis. South Med J 1953;46:551-554.

10. American Psychiatric Association. Diagnostic and statistical manual of mental disorders. 4th ed. Washington, DC:American Psychiatric Association;1994.

11. Linehan MM, Schmidt H 3rd, Dimeff LA, Craft JC, Kanter J, Comtois KA. Dialectical behavior therapy for patients with borderline personality disorder and drug-dependence. Am J Addict 1999;8:279-292.

12. Ehsani AH, Toosi S, Mirshams Shahshahani M, Arbabi M, Noormohammadpour P. Psycho-cutaneous disorders: an epidemiologic study. J Eur Acad Dermatol Venereol 2009; 23:945-947. 